\title{
Tumoral calcinosis in dermatomyositis
}

\author{
Mohammad Khudadah $^{1}$ (D) Ali S. M. Jawad ${ }^{1}$ (D)
}

Received: 11 June 2020 /Revised: 22 June 2020 / Accepted: 25 June 2020 / Published online: 1 July 2020

(C) International League of Associations for Rheumatology (ILAR) 2020

\section{Case}

A 31-year-old Bengali woman complained of discomfort on sitting on hard surfaces over the preceding few weeks. She also felt hard lumps on the junction of the buttocks and legs. Nine years earlier, she was diagnosed with dermatomyositis (DM) (proximal muscle weakness, very high creatine kinase, positive muscle biopsy, heliotrope rash, and interstitial lung disease with positive Jo-1 antibodies). Her DM was very severe especially the lungs requiring prednisolone and intravenous cyclophosphamide for 2 years. Currently, her condition was stable on weekly $12.5 \mathrm{mg}$ methotrexate and $5 \mathrm{mg}$ prednisolone. She walks slowly using a stick.

Physical examination showed multiple hard lumps $(1-2 \mathrm{~cm}$ in diameter) with mild tenderness within the muscles of the buttocks and the upper thighs and the hamstrings. Plain X-ray of the pelvis showed large calcified nodules within the muscles of the pelvic girdle (Fig. 1). Similar calcifications were seen around the muscles of the shoulder girdles. Her serum calcium, phosphate, alkaline phosphate, 25 hydroxy-vitamin $\mathrm{D}$, parathormone and renal function tests were normal. Analysis of the calcified material removed from our patient using Infrared spectroscopy shows the material to be $99 \%$ calcium phosphate as carbonate apatite [Ca10 $(\mathrm{PO} 4 \mathrm{CO} 3 \mathrm{OH}) 6(\mathrm{OH}) 2]$.

There are two types of calcinosis that complicate cases of severe DM; deep tumoral within the affected muscles as in our

Mohammad Khudadah

Mohammad.khudadah@nhs.net

Ali S. M. Jawad

Ali.jawad8@nhs.net

1 Rheumatology Department, Royal London Hospital, Bancroft Road London E1 4DG UK patient or diffuse lacy reticular deposits within the myofascial planes. ${ }^{1}$ In some patients, there is a mixture of both types. The calcinosis of DM is dystrophic.

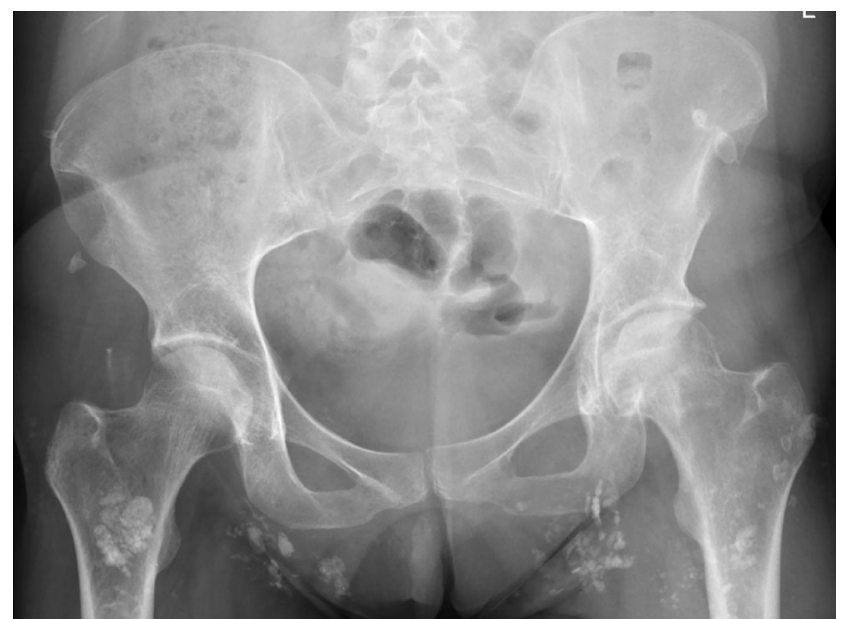

Fig. 1 Plain X-ray of the pelvis showing large calcified nodules within the muscles of the pelvic girdle

\section{Compliance with ethical standards}

The patient has consented to publish her case history and X-rays.

Disclosures None

\section{Reference}

1. Boulman N, Slobodin G, Rozenbaum M, Rosner I (2005) Calcinosis in rheumatic diseases. Semin Arthritis Rheum 34:805-812

Publisher's note Springer Nature remains neutral with regard to jurisdictional claims in published maps and institutional affiliations. 